\title{
Sensitivity of allyl isothiocyanate to induce apoptosis via ER stress and the mitochondrial pathway upon ROS production in colorectal adenocarcinoma cells
}

\author{
JO-HUA CHIANG ${ }^{1}$, FUU-JEN TSAI ${ }^{2-4}$, YUAN-MAN HSU ${ }^{5}$, MEI-CHIN YIN $^{6}$, \\ HONG-YI CHIU ${ }^{7-9}$ and JAI-SING YANG ${ }^{10}$ \\ ${ }^{1}$ Department of Nursing, Chung-Jen Junior College of Nursing, Health Sciences and Management, Chiayi County 62241; \\ ${ }^{2}$ Human Genetics Center, Department of Medical Research, ${ }^{3}$ Department of Medical Genetics, \\ China Medical University Hospital, Taichung 40447; ${ }^{4}$ School of Chinese Medicine, \\ ${ }^{5}$ Department of Biological Science and Technology, China Medical University, Taichung 40402; \\ ${ }^{6}$ Department of Food Nutrition and Health Biotechnology, Asia University, Taichung 41354; \\ ${ }^{7}$ Department of Pharmacy, Hualien Tzu Chi Hospital, Buddhist Tzu Chi Medical Foundation, Hualien 97002; \\ ${ }^{8}$ Master and PhD Program in Pharmacology and Toxicology, School of Medicine, Tzu Chi University, Hualien 97004; \\ ${ }^{9}$ General Education Center, Tzu Chi University of Science and Technology, Hualien 97005; \\ ${ }^{10}$ Department of Medical Research, China Medical University Hospital, China Medical University, \\ Taichung 40442, Taiwan, R.O.C.
}

Received January 10, 2020; Accepted June 29, 2020

DOI: $10.3892 /$ or.2020.7700

\begin{abstract}
Allyl isothiocyanate (AITC), a bioactive phytochemical compound that is a constituent of dietary cruciferous vegetables, possesses promising chemopreventive and anticancer effects. However, reports of AITC exerting antitumor effects on apoptosis induction of colorectal cancer (CRC) cells in vitro are not well elucidated. The present study focused on the functional mechanism of the endoplasmic reticulum (ER) stress-based apoptotic machinery induced by AITC in human colorectal cancer HT-29 cells. Our results indicated that AITC decreased cell growth and number, reduced viability, and facilitated morphological changes of apoptotic cell death. DNA analysis by flow cytometry showed G2/M phase arrest, and alterations in the modulated protein levels caused by AITC were detected via western blot analysis. AITC also triggered vital intrinsic apoptotic factors (caspase-9/caspase-3 activity), disrupted mitochondrial membrane potential, and stimulated
\end{abstract}

Correspondence to: Dr Jai-Sing Yang, Department of Medical Research, China Medical University Hospital, China Medical University, 2 Yude Road, Taichung 40447, Taiwan, R.O.C.

E-mail: jaisingyang@gmail.com

Dr Hong-Yi Chiu, Department of Pharmacy, Hualien Tzu Chi Hospital, Buddhist Tzu Chi Medical Foundation, Sec. 3, 707 Chung-Yang Road, Hualien 97002, Taiwan, R.O.C.

E-mail: hychiu@tzuchi.com.tw

Key words: allyl isothiocyanate, colon cancer cells, apoptosis, ER stress, mitochondria, ROS production mitochondrial-related apoptotic molecules (e.g., cytochrome $c$, apoptotic protease activating factor 1, apoptosis-inducing factor, and endonuclease G). Additionally, AITC prompted induced cytosolic $\mathrm{Ca}^{2+}$ release and $\mathrm{Ca}^{2+}$-dependent ER stress-related signals, such as calpain 1, activating transcription factor $6 \alpha$, glucose-regulated proteins 78 and 94, growth arrest- and DNA damage-inducible protein 153 (GADD153), and caspase-4. The level of reactive oxygen species (ROS) production was found to induce the hallmark of ER stress GADD153, proapoptotic marker caspase-3, and calpain activity after AITC treatment. Our findings showed for the first time that AITC induced G2/M phase arrest and apoptotic death via ROS-based ER stress and the intrinsic pathway (mitochondrial-dependent) in HT-29 cells. Overall, AITC may exert an epigenetic effect and is a potential bioactive compound for CRC treatment.

\section{Introduction}

Colorectal cancer (CRC) is the third leading cause of cancer-related mortality in males and females worldwide, with approximately 243,000 mortalities reported in 2018 (1). The risk factors of CRC development include eating habits, red meat consumption, obesity, high-fat intake, and smoking (2). $\mathrm{CRC}$ is a highly lethal disease, and this aggressive malignancy is strongly invasive and highly metastatic and has a poor prognosis (3). Although most of the primary tumors in CRC can be surgically resected, patients with late-stage CRC have a poor 5-year survival rate (3). After surgical resection, tumor recurrence commonly occurs; thus the main treatment strategies for CRC are consistently unsatisfactory $(3,4)$. Therefore, broadening our understanding of CRC treatment is necessary to develop novel therapeutic targets or 
chemotherapeutic approaches from dietary phytochemicals or natural extracts $(3,5)$.

Numerous epidemiological studies have observed an inverse association between cancers and high dietary consumption of cruciferous vegetables, which is recognized to confer health benefits for reducing the risk of developing the disease and eliciting chemopreventive effects (6). Cruciferae is a family of vegetables, including broccoli, cabbage, cauliflower, and brussels sprouts, which are rich in isothiocyanates (ITCs), a nutraceutical agent with protection against cancer development $(7,8)$. Moreover, ITCs have drawn attention owing to their capability to exert a broad spectrum of antitumor effects (9-11). Allyl isothiocyanate (AITC) is a constituent of naturally occurring ITCs and exerts multiple biological effects (such as anti-microbial, anti-inflammatory, anti- angiogenic and anticancer activities) (12-15). AITC was found to inhibit cell proliferation and to facilitate apoptosis through $\mathrm{Bcl}-2 / \mathrm{Bax}$ imbalanced expression in human renal carcinoma GRC-1 cells (16). AITC was also demonstrated to trigger multiple apoptotic pathways in human breast cancer cell lines (MDA-MB-468, MDA-MB-231 and MCF-7) $(12,17)$. Combined treatment using AITC and sulforaphane (a glucosinolate-derived ITC) was found to synergistically multi-target the system of proliferation and metastasis in human non-small cell lung cancer A549 cells (18). AITC suppressed cell proliferation in bladder cancer RT4 and T24 cells via different mechanisms upon p53 gene expression (19). AITC was also found to exhibit antitumor effects against colorectal adenocarcinoma SW620 cells by inducing G2/M phase arrest and downregulating Cdc25B and Cdc25C levels (20). Recently, AITC was reported to trigger protective autophagy via beclin-1 upregulation in prostate cancer cells (21). We previously found that AITC provokes apoptotic processes in human brain glioma GBM 8401 cells (22) and breast adenocarcinoma MDA-MB-468 cells (12). Additionally, AITC was reported to be involved in the inhibition of cell metastasis in various cancer types such as colorectal adenocarcinoma, bladder cancer and hepatoma (23-25).

Although different functions related to the anticancer properties of AITC have been reported (23-28), the role of AITC in human colorectal adenocarcinoma cells in the adaptation to endoplasmic reticulum (ER) stress and cell apoptosis has not yet been fully characterized. In this study, we aimed to understand how AITC stimulates ER stress and the mitochondrial-dependent apoptotic pathway in colon cancer HT-29 cells and whether the involvement of reactive oxygen species (ROS) production is required.

\section{Materials and methods}

Chemicals and reagents. AITC, 1,2-bis(2-aminophenoxy) ethane- $N, N, N^{\prime}, N^{\prime}$-tetraacetic acid tetrakis(acetoxymethyl ester) (BAPTA/AM), calpeptin, 4',6-diamidino-2-phenylindole (DAPI), N-acetylcysteine (NAC), propidium iodide (PI), and trypan blue were obtained from Sigma-Aldrich (Merck KGaA). 2',7'-Dichlorodihydrofluorescein diacetate ( $\left.\mathrm{H}_{2} \mathrm{DCFDA}\right), 3,3^{\prime}$-dihexyloxacarbocyanine iodide [DiOC 6 (3)], fetal bovine serum (FBS), 4-(6-acetoxymethoxy-2,7-dichloro3-oxo-9-xanthenyl)-4'-methyl-2,2'(ethylenedioxy)dianiline- $N$, $N, N^{\prime}, N^{\prime}$-tetraacetic acid tetrakis(acetoxymethyl) ester
(fluo-3/AM), L-glutamine, Roswell Park Memorial Institute (RPMI)-1640 medium, penicillin, streptomycin, and trypsin-EDTA were obtained from Thermo Fisher Scientific, Inc. Caspase-3 and Caspase-9 Colorimetric Assay Kits were purchased from R\&D Systems. Caspase-3 inhibitor Z-DEVD-FMK and caspase-9 inhibitor Z-LEHD-FMK were purchased from Merck Millipore. All primary antibodies were purchased from Cell Signaling Technology, Inc. or Santa Cruz Biotechnology, Inc. The goat anti-rabbit or anti-mouse immunoglobulin G ( $\mathrm{IgG}$ ) secondary antibodies conjugated with horseradish peroxidase (HRP) were also obtained from Cell Signaling Technology, Inc. Mitochondria/Cytosol Fractionation Kit was purchased from BioVision, Inc. The goat anti-mouse IgG-phycoerythrin (PE) secondary antibody was also obtained from Santa Cruz Biotechnology, Inc.

Cell culture. Human colorectal adenocarcinoma cell line HT-29 was obtained from the Bioresources Collection and Research Center, Food Industry Research and Development Institute (Hsinchu, Taiwan) and authenticated by short tandem repeat (STR) profiling (Mission Biotech Co., Ltd., Taipei, Taiwan). The cells were placed in $75-\mathrm{cm}^{2}$ (75T) tissue culture flasks and cultured at $37^{\circ} \mathrm{C}$ under a humidified $5 \% \mathrm{CO}_{2}$ atmosphere in RPMI-1640 medium with $2 \mathrm{mM}$ L-glutamine, 10\% FBS, $100 \mathrm{U} / \mathrm{ml}$ penicillin, and $100 \mu \mathrm{g} / \mathrm{ml}$ streptomycin.

Cell counting and viability assays and morphological analysis. HT-29 cells ( $2 \times 10^{5}$ cells/well) were individually maintained in 12 -well plates and then treated with $0,5,10$ and $20 \mu \mathrm{M}$ of AITC for 24 and $48 \mathrm{~h}$. At the end of the treatments, the cell morphology changes were examined and photographed under a phase-contrast microscope. Subsequently, the cells were harvested to determine the cell number using $0.3 \%$ Trypan blue stain via an Invitrogen Countess Automated Cell Counter (Thermo Fisher Scientific, Inc.), and cell viability was assessed using MTT assay, as previously described $(29,30)$.

DNA content and sub-G1 population analysis. HT-29 cells ( $2 \times 10^{5}$ cells/well) in 12 -well plates were treated with $0,5,10$ and $20 \mu \mathrm{M}$ of AITC for $24 \mathrm{~h}$. Then, the cells were harvested and fixed in $70 \%$ ethanol at $4^{\circ} \mathrm{C}$ overnight. DNA was stained with a PI solution $(40 \mu \mathrm{g} / \mathrm{ml}$ PI, $0.1 \mathrm{mg} / \mathrm{ml}$ RNase A, and $0.1 \%$ Triton X-100) in phosphate-buffered saline for $30 \mathrm{~min}$ in the dark. All samples were analyzed via a BD FACSCalibur Flow Cytometry System (BD Biosciences), and the cell cycle distribution and sub-G1 phase (apoptotic cells) were determined, as previously described $(31,32)$.

Western blot analysis. HT-29 cells ( $1 \times 10^{6}$ cells) in $75 \mathrm{~T}$ flasks were treated with $0,5,10$ and $20 \mu \mathrm{M}$ of AITC and incubated for the indicated time interval. The cells were harvested following each treatment, and the total proteins were collected and lysed, as previously described $(33,34)$. The proteins of the mitochondrial and cytosolic fraction were isolated according to the manufacturing protocol of the Mitochondria/Cytosol Fractionation Kit (BioVision, Inc.). The protein content of the supernatant was measured using a Bio-Rad Protein Assay Kit (Bio-Rad Laboratories, Inc.). An amount of $40 \mu \mathrm{g}$ protein from each sample was dissolved using $10 \%$ sodium dodecyl sulfate-polyacrylamide gel electrophoresis and transferred 
to an Immobilon-P Transfer Membrane (Merck Millipore). Western blotting was performed to detect the expression of cyclin A (cat. no. 4656, dilution 1:1,000), cyclin B (cat. no. 12231, dilution 1:1,000), cyclin-dependent kinase 1 (CDK1) (cat. no. 9116, dilution 1:1,000), checkpoint kinase 1 (Chk1) (cat. no. 2656, dilution 1:1,000), Wee1 (cat. no. 4936, dilution 1:1,000), cytochrome $c$ (cat. no. 4280, dilution 1:1,000), apoptotic protease activating factor 1 (Apaf-1) (cat. no. 8969, dilution 1:1,000), apoptosis-inducing factor (AIF) (cat. no. 4642, dilution 1:1,000), endonuclease G (Endo G) (cat. no. 4969, dilution 1:1,000), caspase-9 (cat. no. 9508, dilution 1:1,000), caspase-3 (cat. no. 14220, dilution 1:1,000) (Cell Signaling Technology, Inc.), calpain 1 (cat. no. sc-271313, dilution 1:1,000), activating transcription factor $6 \alpha$ (ATF-6 $\alpha$ ) (cat. no. sc-166659, dilution 1:1,000), $78 \mathrm{kDa}$ glucose-regulated protein (GRP78) (cat. no. sc-13539, dilution 1:1,000), GRP94 (cat. no. sc-32249, dilution 1:1,000), growth arrest- and DNA damage-inducible protein 153 (GADD153) (cat. no. sc-7351, dilution 1:1,000), and caspase-4 (cat. no. sc-56056, dilution 1:1,000) (Santa Cruz Biotechnology, Inc.). Each blot was soaked in a blocking buffer (5\% nonfat powdered milk and $0.05 \%$ Tween-20 in $1 \mathrm{X}$ Tris-buffered saline at $\mathrm{pH} 7.6$ ) at room temperature for $1 \mathrm{~h}$ and then incubated with individual primary monoclonal antibodies in the blocking buffer at $4^{\circ} \mathrm{C}$ overnight. Thereafter, the blots were probed with appropriate HRP-conjugated secondary antibodies [anti-rabbit IgG (cat. no. 7074, dilution 1:10,000) and anti-mouse IgG (cat. no. 7076, dilution 1:10,000)] (Cell Signaling Technology, Inc.), as previously described $(30,33,35)$. To ensure equal protein loading, each membrane was stripped and reprobed with an anti- $\beta$-actin antibody. Quantitative analysis of each immunoreactive blot was performed to measure the intensity of the band signal via the National Institutes of Health ImageJ $1.52 \mathrm{v}$ program.

Assays for caspase-9 and caspase-3 activity. HT-29 cells $\left(1 \times 10^{6}\right.$ cells $)$ in $75 \mathrm{~T}$ flasks were exposed to $0,5,10,15$ and $20 \mu \mathrm{M}$ of AITC for $24 \mathrm{~h}$ to assess the activities of caspase- 9 and caspase-3, which were determined using Caspase- 3 and Caspase-9 Colorimetric Assay Kits in accordance with the manufacturer's protocols (R\&D Systems).

Detection of mitochondrial membrane potential ( $\Delta \Psi \mathrm{m}), \mathrm{Ca}^{2+}$ generation, and ROS production by flow cytometry. HT-29 cells $\left(2 \times 10^{5}\right.$ cells/well) were maintained in 12 -well plates and then incubated with 5, 10, 15 and $20 \mu \mathrm{M}$ AITC for $6 \mathrm{~h}$ to individually measure the changes in $\Delta \Psi \mathrm{m}, \mathrm{Ca}^{2+}$ release, and $\mathrm{ROS}$ production. Subsequently, the cells were harvested and resuspended in $500 \mu \mathrm{l}$ of $100 \mathrm{nM} \mathrm{DiOC}_{6}(3)$ for $\Delta \Psi \mathrm{m}, 2.5 \mu \mathrm{g} / \mathrm{ml}$ fluo-3/AM for intracellular $\mathrm{Ca}^{2+}$, and $10 \mu \mathrm{M} \mathrm{H} \mathrm{H}_{2} \mathrm{DCFDA}$ for ROS determination. Thereafter, all cells were incubated at $37^{\circ} \mathrm{C}$ for $30 \mathrm{~min}$ and further analyzed by flow cytometry for mean fluorescence intensity, as previously described $(36,37)$.

Calpain activity assay. HT-29 cells ( $2 \times 10^{5}$ cells/well) were plated in 12-well plates and then pretreated with or without $5 \mu \mathrm{M}$ BAPTA/AM (a Ca ${ }^{2+}$ chelator), $20 \mu \mathrm{M}$ calpeptin (a cell-permeable calpain inhibitor), and NAC (an ROS scavenger) for $1 \mathrm{~h}$. The cells were loaded with a calpain proteasome substrate (Suc-Leu-Leu-Val-Tyr-AMC) (Enzo Life Sciences), as previously described (38), prior to incubation with $10 \mu \mathrm{M}$
AITC for $6 \mathrm{~h}$ to measure changes in calpain activity. Proteolysis of the fluorescent probe was monitored via a PerkinElmer HTS 7000 Series Bioassay Reader with filter settings of $360 \pm 20 \mathrm{~nm}$ for excitation and $460 \pm 20 \mathrm{~nm}$ for emission.

Effects of the caspase-3/caspase-9 inhibitors (Z-DEVD-FMK and Z-LEHD-FMK), Ca ${ }^{2+}$ chelator (BAPTA/AM), calpain-specific inhibitor (calpeptin), and ROS scavenger (NAC) on cell viability or alterations in protein levels after AITC challenge. HT-29 cells ( $2 \times 10^{5}$ cells/well) in 12-well plates were individually pretreated with $20 \mu \mathrm{M}$ Z-DEVD-FMK, $20 \mu \mathrm{M}$ Z-LEHD-FMK, $5 \mu \mathrm{M}$ BAPTA/AM, $20 \mu \mathrm{M}$ calpeptin, and $10 \mathrm{mM}$ NAC for $2 \mathrm{~h}$ prior to exposure to $10 \mu \mathrm{M}$ AITC for $24 \mathrm{~h}$. The cells from each treatment group were harvested to measure the percentage of viable cells via MTT assay, as previously described $(9,36)$. The protein levels were detected using western blot analysis, as previously stated.

Immunofluorescence staining by confocal microscopy. HT-29 cells $\left(5 \times 10^{4}\right.$ cells/well) in 4-well chamber slides were preincubated with or without $10 \mathrm{mM}$ NAC for $2 \mathrm{~h}$ prior to $10 \mu \mathrm{M}$ AITC treatment for $24 \mathrm{~h}$. The cells were fixed and blocked with $2.5 \%$ bovine serum albumin for $1 \mathrm{~h}$ at room temperature. The samples were then stained with anti-calpain 1 (cat. no. sc-271313, dilution 1:100) at $4^{\circ} \mathrm{C}$ overnight following labeling with goat anti-mouse IgG-PE (cat. no. sc-3738, dilution 1:200) for $1 \mathrm{~h}$. Thereafter, the cell nuclei were counterstained with $1 \mu \mathrm{g} / \mathrm{ml}$ DAPI for $15 \mathrm{~min}$ at room temperature. Finally, the slides were mounted with coverslips, as previously described $(36,37)$, and photomicrographs were then analyzed via Andor Dragonfly High Speed Confocal System (ANDOR, Dragonfly 200) and High Content Image System (Molecular Devices, ImageXpress Micro Confocal).

Statistical analysis. The results are expressed as mean \pm standard deviation (SD) (n=3), and significance among multiple experimental groups was estimated using one-way analysis of variance (ANOVA), followed by Dunnett's test or Tukey's post hoc test using SPSS 16.0 software (SPSS, Inc.). A P-value of $<0.05$ was considered statistically significant.

\section{Results}

AITC reduces the survival rate and triggers apoptotic cell morphology changes in human CRC HT-29 cells. We first investigated the potential of AITC to reduce the growth of colon cancer in vitro. The total cell number of each treatment group was determined using the Countess Automated Cell Counter. Treatment with 5-20 $\mu \mathrm{M}$ of AITC significantly suppressed cell growth and number compared with the untreated control cells (Fig. 1A). Furthermore, AITC (5, 10, and $20 \mu \mathrm{M})$ significantly reduced cell viability (Fig. 1B). These effects were concentration and time dependent. Cell morphology was also examined and photographed and showed apoptotic changes (cell shrinkage, rounding, and membrane blebbing) compared with an untreated control (Fig. 1C). Therefore, we suggest that AITC inhibited cell growth, possibly via the apoptotic characteristics observed in HT-29 cells following AITC treatment.

AITC causes G2/M phase arrest and alters its regulated protein levels in HT-29 cells. To evaluate the dynamics of 
A
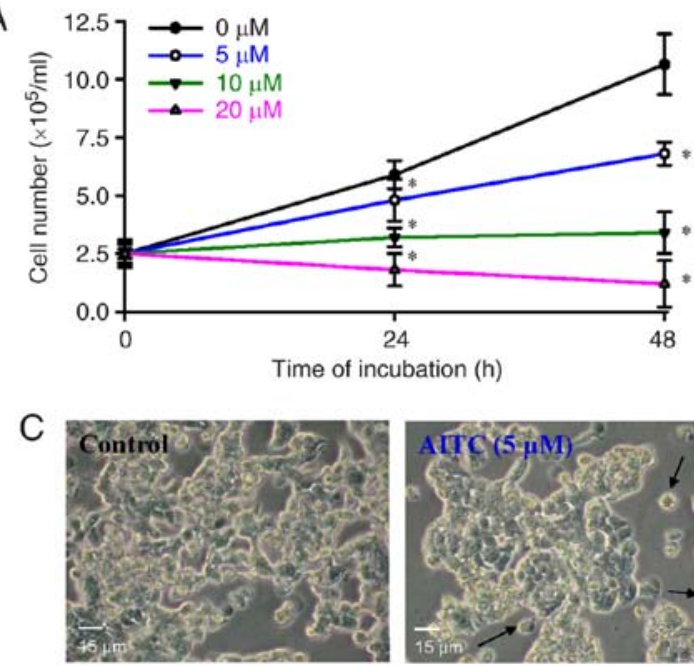
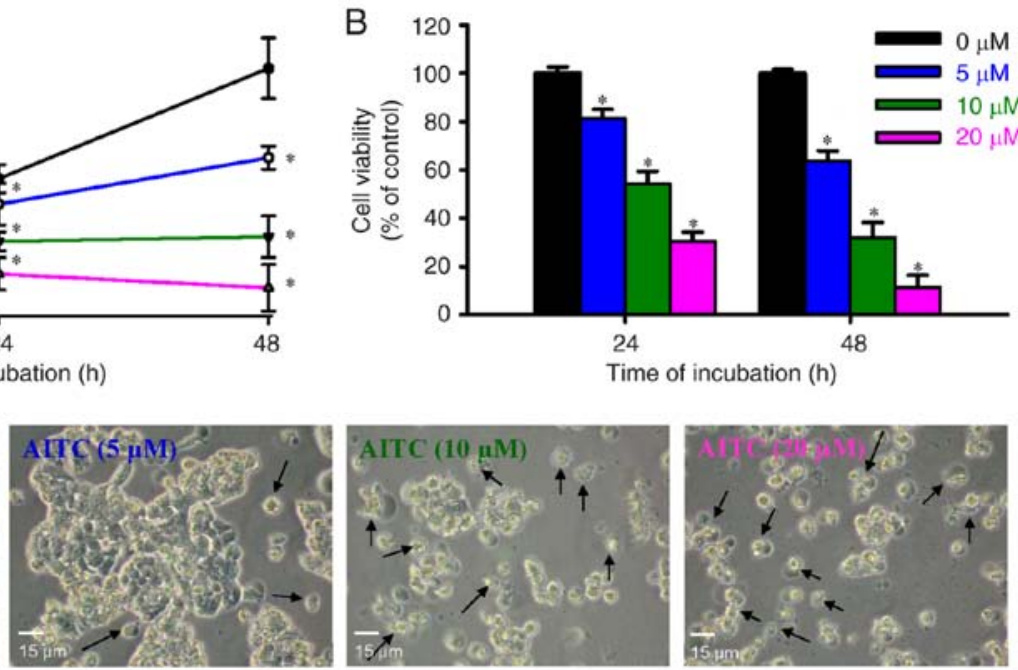

Figure 1. Effects of AITC on the number, viability, and morphology of HT-29 cells. The cells were incubated with AITC ( 0,5 , 10 and $20 \mu \mathrm{M})$ for 24 and $48 \mathrm{~h}$. (A) Cell counting assay was performed via the trypan blue exclusion method. (B) The viability of HT-29 cells was detected using MTT assay. Each point represents mean $\pm \mathrm{SD}$ of three experiments; ${ }^{*} \mathrm{P}<0.05$ vs. the control (Dunnett's post hoc test after ANOVA). (C) After treatment with AITC for 24 h, cells in each well were visualized and photographed using phase-contrast microscopy at x 200 magnification. Representative images are shown. The arrows ( $\uparrow$ ) indicate apoptotic cells. Scale bar, $15 \mu \mathrm{m}$. AITC, allyl isothiocyanate.

cell cycle distribution after AITC treatment, DNA content was measured. After exposure to $0-20 \mu \mathrm{M}$ AITC for $24 \mathrm{~h}$, the cells in the $\mathrm{G} 2 / \mathrm{M}$ phase were markedly increased compared with the control, and this effect was concentration dependent (Fig. 2A and Table SI). Moreover, treatment with $20 \mu \mathrm{M}$ AITC dramatically enhanced the sub-G1 phase (apoptotic population) from $2.4 \pm 0.7 \%$ (control) to $30.2 \pm 4.1 \%$. AITC arrested the cell cycle at the $\mathrm{G} 2 / \mathrm{M}$ phase by exerting inhibitory effects on cell growth, and apoptotic features were observed (Fig. 2A and B). To explore the molecular level of AITC-provoked G2/M phase arrest further, we assessed the levels of the key regulatory proteins of the cell cycle checkpoints. The protein levels of cyclin B and CDK1 were markedly decreased, but those of Chk1 and Weel were increased after AITC challenge (Fig. 2C). These results indicate that AITC suppresses cell proliferation due to cell cycle arrest at the G2/M phase in HT-29 cells.

AITC provokes apoptosis via the intrinsic caspase cascade-dependent process in HT-29 cells. To ascertain whether AITC-induced apoptosis is employed via the intrinsic pathway, the cells were pretreated with or without protease inhibitors prior to incubation with AITC for $24 \mathrm{~h}$. AITC exposure for $24 \mathrm{~h}$ significantly stimulated caspase-9 (Fig. 3A) and caspase-3 (Fig. 3B) activities in a concentration-dependent manner. To confirm whether caspase-9/caspase-3-dependent signaling was the main contributor to AITC-induced cell apoptosis, both of their specific inhibitors were applied to test cell viability prior to AITC exposure. Our results demonstrated that Z-LEHD-FMK (Fig. 3C) and Z-DEVD-FMK (Fig. 3D) significantly abolished AITC-reduced cell viability. Thus, AITC elicited apoptosis via an intrinsic molecular pathway (caspase-9/-3-dependent) in HT-29 cells.

AITC-triggered apoptotic signaling results from mitochondrial cell death effectors in HT-29 cells. To verify whether AITC-induced apoptosis was mediated through a mitochondrial-dependent pathway, the cells were exposed to $0-20 \mu \mathrm{M}$ AITC for $6 \mathrm{~h}$, and then the level of $\Delta \Psi \mathrm{m}$ was measured. AITC significantly disrupted the $\Delta \Psi \mathrm{m}$ level in a concentration-dependent manner (Fig. 4A). To clarify the downstream molecular regulators of $\Delta \Psi \mathrm{m}$ dissipation, we determined the levels of mitochondrial-associated proteins and intrinsic caspase proteases by western blot analysis. AITC noticeably increased the protein expression levels of cytochrome $c$, Apaf-1, AIF, Endo G, cleaved caspase-9, and cleaved caspase-3 (Fig. 4B). Additionally, AITC markedly decreased mitochondrial cytochrome $c$ levels (Fig. 4C, top); however, cytochrome $c$ levels in the cytoplasmic fraction were dramatically increased after AITC exposure (Fig. 4C, bottom). These data demonstrated that manifestation of HT-29 cell apoptosis by AITC occurred via mitochondrial dysfunction and the activation of the intrinsic pathway.

AITC elicits $\mathrm{Ca}^{2+}$-dependent ER stress-mediated proapoptotic signaling in HT-29 cells. To elucidate the upstream pathway of AITC-induced apoptotic machinery, we determined the level of cytosolic $\mathrm{Ca}^{2+}$ release in response to AITC treatments for up to $6 \mathrm{~h}$. AITC $(5-20 \mu \mathrm{M})$ significantly promoted intracellular $\mathrm{Ca}^{2+}$ release in a concentration-dependent manner (Fig. 5A). Additionally, AITC at $10 \mu \mathrm{M}$ significantly increased the accumulation of calpain activity compared with the control cells (Fig. 5B). BAPTA/AM and calpeptin significantly neutralized AITC-activated calpain activity compared with the AITC-treated only cells (Fig. 5B). Thus, AITC stimulated the cytosolic $\mathrm{Ca}^{2+}$ signal to trigger the mitochondrial-mediated apoptotic events. AITC-induced apoptosis might be implicated in ER stress-mediated biochemical signaling. Subsequently, we examined ER stress-associated protein levels. The protein levels of calpain 1, ATF-6 $\alpha$, GRP78, GRP94, GADD153, and caspase- 4 were upregulated in a concentration-dependent manner (Fig. 5C). To confirm $\mathrm{Ca}^{2+}$-mediated ER stress and apoptosis induced by AITC, the cells were preincubated with BAPTA/AM and calpeptin prior to AITC exposure to assess cell viability. Both BAPTA/AM and calpeptin effectively 
A

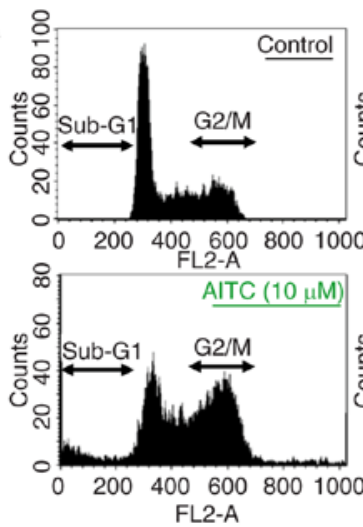

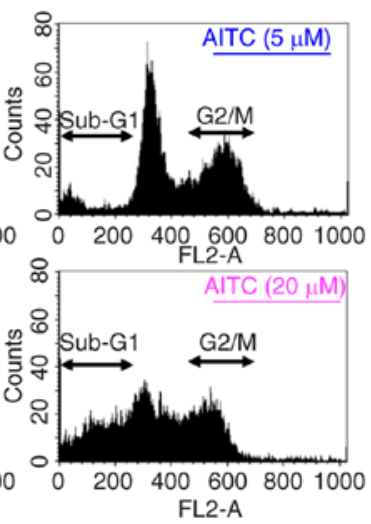
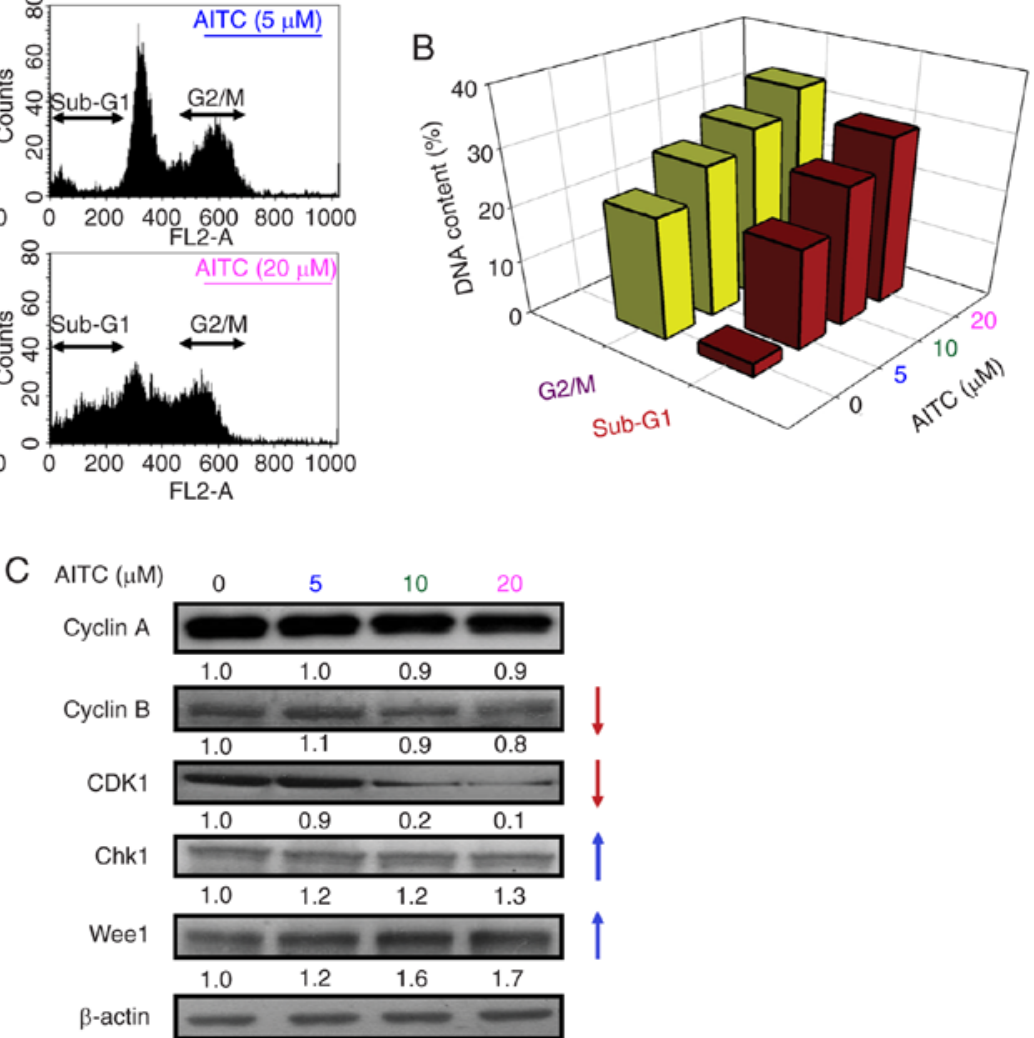

Figure 2. Effects of AITC on cell cycle progression and G2/M phase-regulated protein levels of HT-29 cells. The cells were exposed to various concentrations $(0,5,10$ and $20 \mu \mathrm{M})$ of AITC for $24 \mathrm{~h}$. (A) Representative images of the cell cycle distribution, as determined using flow cytometric analysis. (B) Quantification of G2/M phase and sub-G1 population. (C) The total protein in the cell extracts was subjected to western blot to detect G2/M progression-associated proteins (cyclin A, cyclin B, CDK1, Chk1 and Wee1). All blots were normalized to $\beta$-actin to ensure the same amount of loading of each sample across all samples. AITC, allyl isothiocyanate; CDK1, cyclin-dependent kinase 1; Chk1, checkpoint kinase 1.
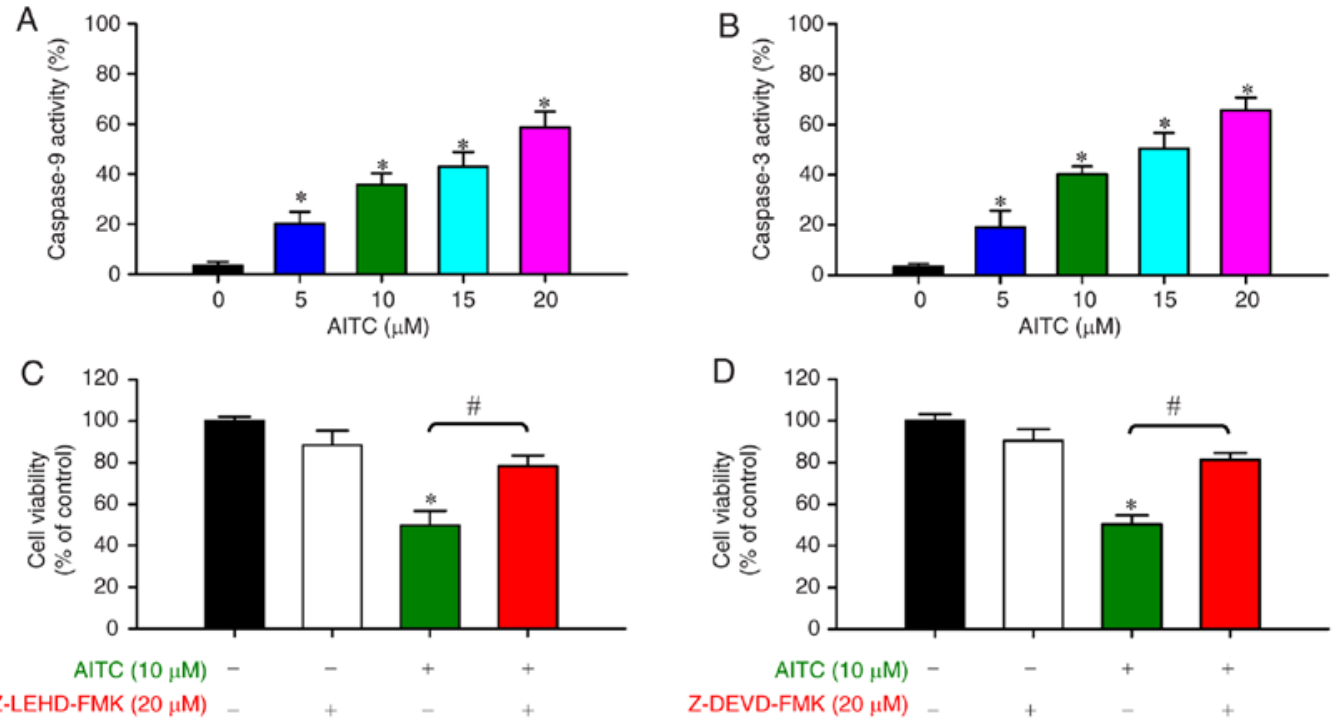

Figure 3. Effects of AITC on caspase- 9 and caspase- 3 activities of HT- 29 cells. Cells were treated with AITC $(0,5,10,15$ and $20 \mu \mathrm{M})$ for $24 \mathrm{~h}$. Cell lysates were harvested, and (A) caspase-9 and (B) caspase-3 activities were determined, as described in Materials and methods. "P $<0.05$ vs. the control; statistical significance was determined by ANOVA (Dunnett's test). The cells were incubated with $10 \mu \mathrm{M}$ AITC for $24 \mathrm{~h}$ after pretreatment with or without (C) Z-LEDH-FMK ( $20 \mu \mathrm{M}$, a caspase-9 inhibitor) and (D) Z-DEVD-FMK ( $20 \mu \mathrm{M}$, a caspase-3 inhibitor) for $2 \mathrm{~h}$ to monitor cell viability via MTT assay. ${ }^{*} \mathrm{P}<0.05 \mathrm{vs.}$ the control and ${ }^{~} \mathrm{P}<0.05$ vs. AITC-treated only cells; statistically significant differences were determined by ANOVA (Tukey's test). Each point represents the mean \pm SD of three experiments. AITC, allyl isothiocyanate.

reversed AITC-induced cell death (Fig. 5D). Hence, the activation of $\mathrm{Ca}^{2+}$ signal-mediated ER stress was necessary for the AITC-triggered intrinsic apoptotic mechanism of HT-29 cells. 

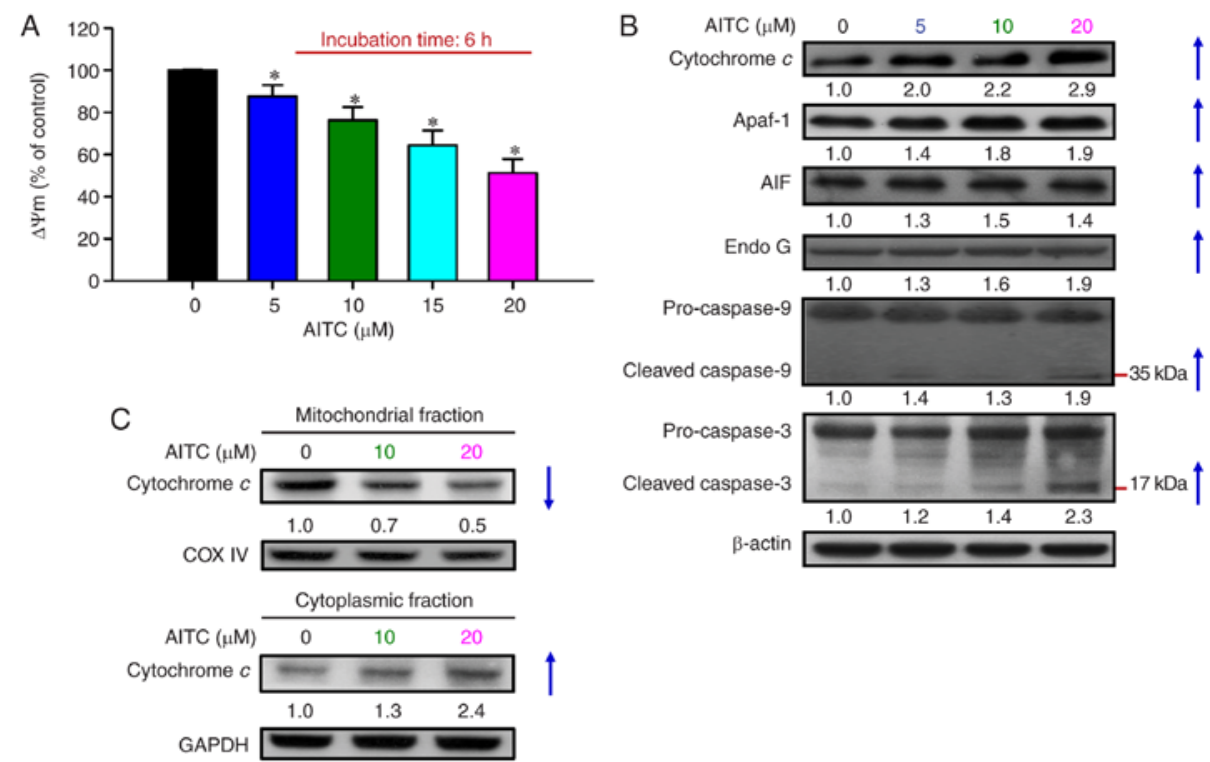

Figure 4. Effects of AITC on the mitochondrial-dependent apoptotic pathway of HT-29 cells. (A) The cells were incubated with AITC (0, 5, 10, 15 and $20 \mu \mathrm{M})$ for $6 \mathrm{~h}$ and then harvested to examine the level of $\Delta \Psi \mathrm{m}$ via $\mathrm{DiOC}_{6}(3)$ and flow cytometry. Each point represents the mean $\pm \mathrm{SD}$ of three experiments; ${ }^{*} \mathrm{P}<0.05$ vs. the control (Dunnett's test after ANOVA). (B) Cells were exposed to the indicated concentrations of AITC for $24 \mathrm{~h}$, and the cell fraction was prepared and analyzed via western blot analysis to estimate the levels of cytochrome $c$, Apaf-1, AIF, Endo G, caspase-9 and caspase-3 protein expression. All blots were normalized to $\beta$-actin to ensure the same amount of loading of each sample across all samples. (C) The mitochondrial (top) and cytoplasmic (bottom) fractions were prepared to detect cytochrome $c$ trafficking via western blot analysis. COX IV and GAPDH were analyzed to ensure the same amount of loading. AITC, allyl isothiocyanate; Apaf-1, apoptotic protease activating factor 1; AIF, apoptosis-inducing factor; Endo G, endonuclease G.
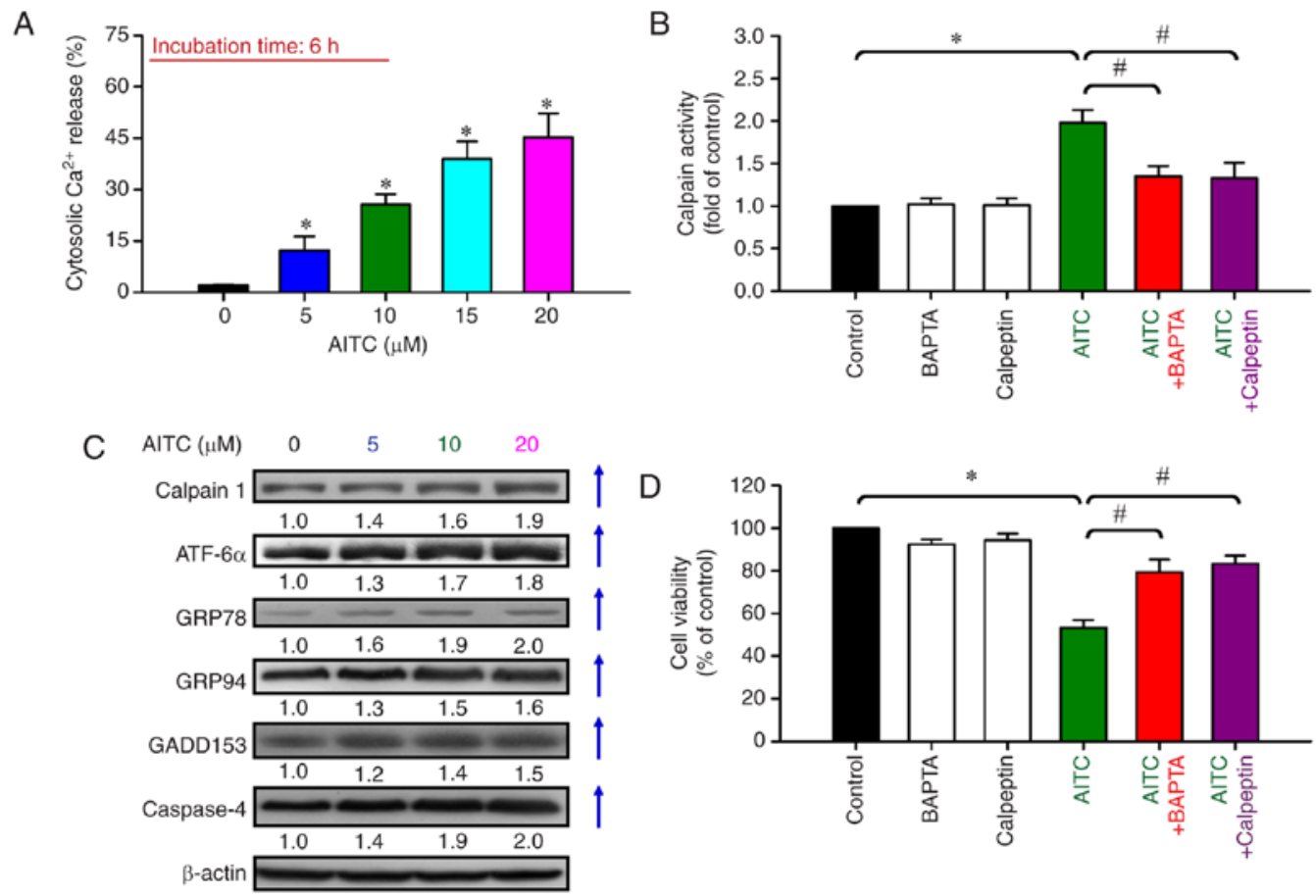

Figure 5. Effects of AITC on cytosolic $\mathrm{Ca}^{2+}$ and ER stress signaling of HT-29 cells. (A) Cells were treated with AITC $(0,5,10,15$ and $20 \mu \mathrm{M})$ for $6 \mathrm{~h}$, and the level of cytosolic $\mathrm{Ca}^{2+}$ was assessed via fluo-3/AM and flow cytometry. " $\mathrm{P}<0.05$ vs. the control; statistical significance was determined by ANOVA (Dunnett's test). (B) The cells were pretreated with or without $5 \mu \mathrm{M}$ BAPTA/AM or $20 \mu \mathrm{M}$ calpain for $2 \mathrm{~h}$ and then exposed to $10 \mu \mathrm{M}$ AITC for $24 \mathrm{~h}$. The cells were harvested and examined for calpain activity. (C) The protein levels of calpain 1, ATF-6 $\alpha$, GRP78, GRP94, GADD153, and caspase-4 were determined using western blot analysis. All blots were normalized to $\beta$-actin to ensure the same amount of loading of each sample across all samples. (D) Cell viability was detected using MTT assay. " $\mathrm{P}<0.05$ vs. the control and ${ }^{\#} \mathrm{P}<0.05$ vs. AITC-treated only cells; statistically significant differences were determined by ANOVA (Tukey's test). Each point represents the mean \pm SD of three experiments; AITC, allyl isothiocyanate; ER, endoplasmic reticulum; ATF- $6 \alpha$, activating transcription factor $6 \alpha$; GRP78, 78 kDa glucose-regulated protein; GRP94, 94 kDa glucose-regulated protein; GADD153, growth arrest- and DNA damage-inducible protein 153. 
A

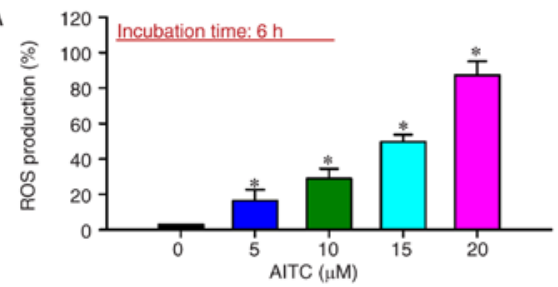

C

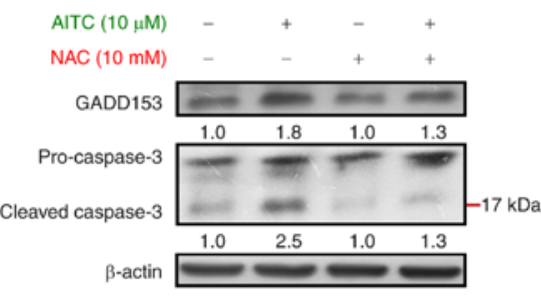

E
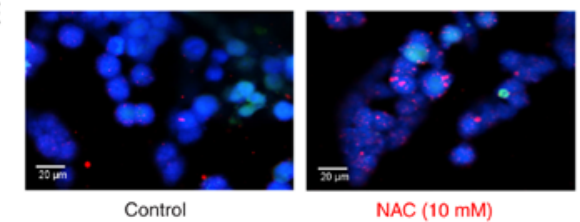

NAC (10 mM)
B

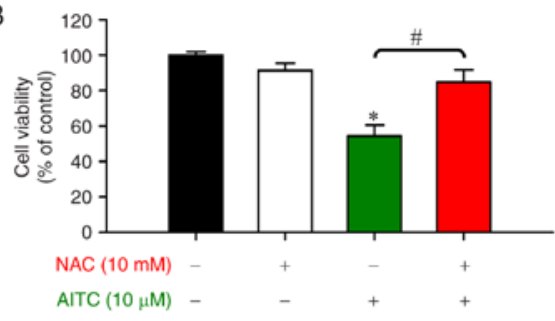

D
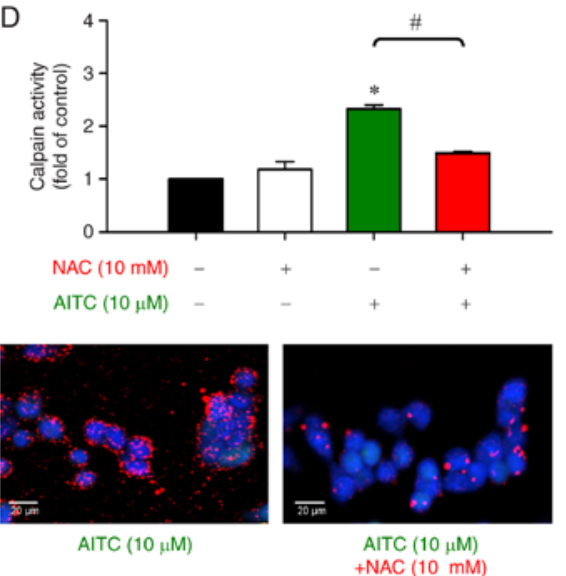

Figure 6. Effects of AITC on ROS production, GADD153 (the hallmark of ER stress), and caspase-3 (an apoptotic marker) of HT-29 cells. (A) Cells were incubated with or without 5, 10, 15 and $20 \mu \mathrm{M}$ of AITC for $6 \mathrm{~h}$, and the level of ROS generation was measured using ROS indicator $\mathrm{H}_{2}$ DCFDA and flow cytometry. ${ }^{*} \mathrm{P}<0.05$ vs. the control; statistical significance was determined by ANOVA (Dunnett's test). (B) The cells were preincubated with or without $10 \mathrm{mM}$ NAC for $2 \mathrm{~h}$ prior to $10 \mu \mathrm{M}$ AITC exposure for $24 \mathrm{~h}$. Cell viability was analyzed using MTT assay. (C) After AITC exposure for $24 \mathrm{~h}$, the cells were collected and the protein levels of GADD153 and caspase-3 were estimated via western blot analysis. All blots were normalized to $\beta$-actin to ensure the same amount of loading of each sample across all samples. (D) After pretreatment with or without $10 \mathrm{mM} \mathrm{NAC}$ for $2 \mathrm{~h}$, the cells were exposed to $10 \mu \mathrm{M}$ AITC exposure for $24 \mathrm{~h}$ and then monitored for calpain activity. ${ }^{*} \mathrm{P}<0.05$ vs. the control and ${ }^{~} \mathrm{P}<0.05$ vs. AITC-treated only cells; statistically significant differences were determined by ANOVA (Tukey's test). Each point represents mean \pm SD of three experiments; (E) The protein expression of calpain 1 was visualized, and the photomicrographs were analyzed via immunofluorescence staining using confocal microscopy of calpain 1 (red, PE-labeled) and nuclei (blue, DAPI-stained). Scale bar, $20 \mu \mathrm{m}$. AITC, allyl isothiocyanate; ROS, reactive oxygen species; ER, endoplasmic reticulum; GADD153, growth arrest- and DNA damage-inducible protein 153.

treated with (0-20 $\mu \mathrm{M})$ AITC for $6 \mathrm{~h}$. The levels of ROS accumulation were measured. AITC significantly increased ROS production in a concentration-dependent manner (Fig. 6A). To confirm that AITC-triggered ROS formation led to cytotoxicity and apoptotic effect, the cells were pretreated with $10 \mathrm{mM}$ NAC prior to AITC exposure. The antioxidant pretreatment abrogated AITC-inhibited cell viability compared with the AITC-treated only cells (Fig. 6B). To clarify the role of ROS in the ER stress-related apoptotic mechanism further after AITC exposure, the hallmark of ER stress GADD153 and apoptotic executioner caspase- 3 were monitored. Although the relative protein expression levels of GADD153 and cleaved caspase-3 were markedly upregulated following AITC treatment, the upregulated protein levels were dramatically blocked by the antioxidant NAC (Fig. 6C). Our results imply that ROS production induced by AITC led to the activation of ER stress and caspase-3-dependent apoptosis. Furthermore, to confirm the role of ROS generation in $\mathrm{Ca}^{2+}$-dependent ER stress induced

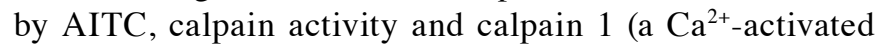
intracellular proteinase) protein expression were investigated. The ROS scavenger NAC effectively inhibited calpain activity (Fig. 6D) and calpain 1 levels (Fig. 6E) induced by AITC exposure. Our data demonstrated that ROS production majorly regulated AITC-triggered $\mathrm{Ca}^{2+}$-mediated ER stress and cell apoptosis. These findings further support the concept that AITC caused G2/M phase arrest via the Weel/Chk1 and CDK1/cyclin B pathways. Our results also provide bimolecular evidence that AITC-induced ROS formation resulted in ER stress, intracellular $\mathrm{Ca}^{2+}$ release, and mitochondrial-mediated cell apoptosis in human colorectal adenocarcinoma HT-29 cells (Fig. 7).

\section{Discussion}

Colorectal cancer (CRC) is currently a major life-threatening malignant tumor, and the high-risk factors involved in CRC development include dietary and lifestyle factors $(1,3)$. The common treatments for CRC include either standard chemotherapy or targeted therapy following complete surgical resection (39). However, the current CRC treatment strategies remain unsatisfactory and the number of therapeutic approaches and screening attempts for patients with CRC is increasing (40). Cruciferous vegetables are widely and often frequently consumed by humans (9), and a high dietary intake of these vegetables has been considered to be associated with a low risk of CRC in the involvement of epigenetic regulation $(6,41)$. Moreover, abundant glucosinolates and their hydrolysis products, such as indoles and isothiocyanates (ITCs), are included $(7,8)$. Allyl isothiocyanate (AITC) belongs to the ITC family and exerts several vital biological effects, including antitumor and anticancer cell proliferation effects on cultured cancer cell lines and animal tumor models $(13,42)$. Therefore, AITC is a health-promoting phytochemical compound that possesses preventive effects and may be a potential therapeutic agent. 


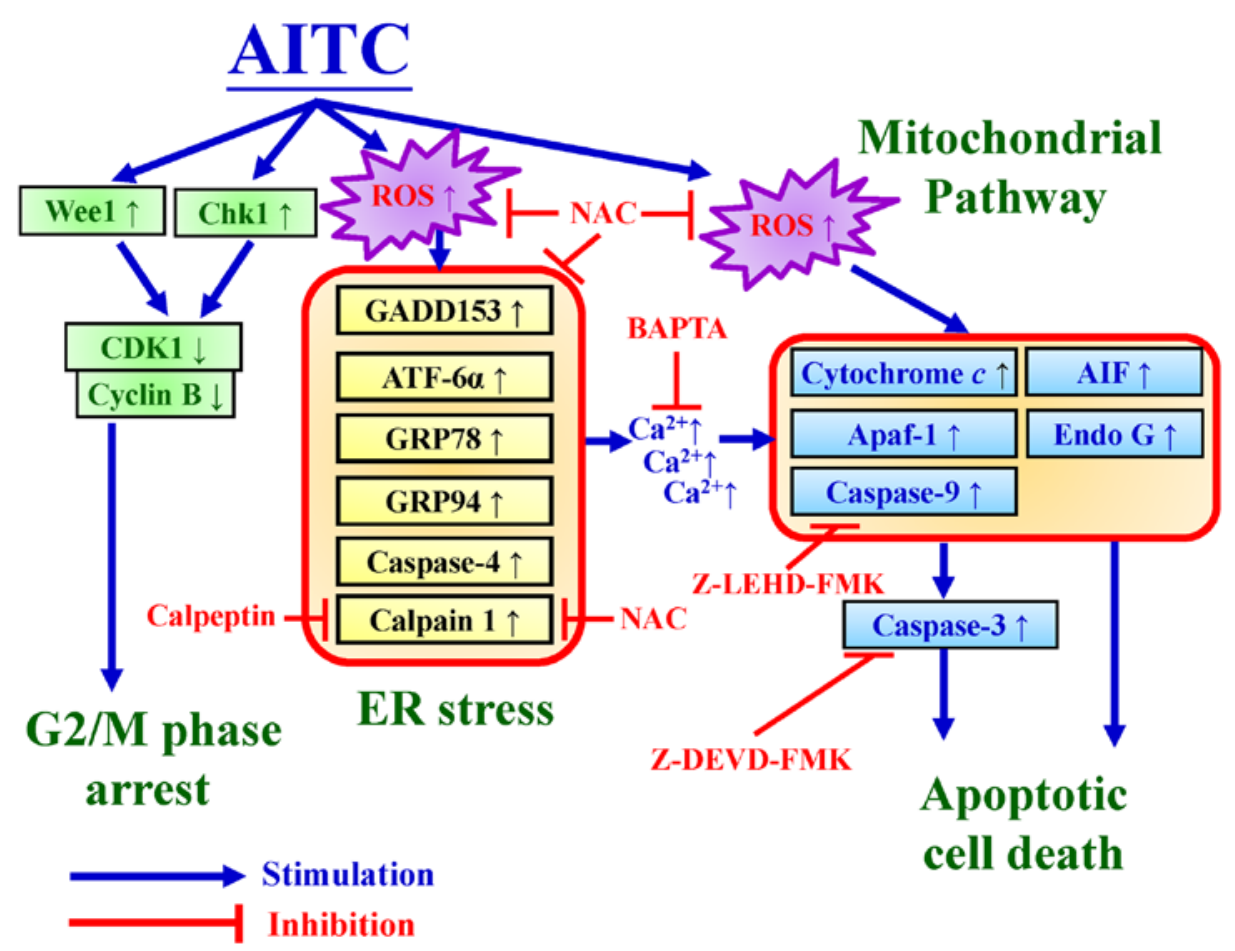

Figure 7. Schematic diagram of the interplay among G2/M phase arrest, ER stress, and mitochondrial-dependent apoptosis in human colorectal adenocarcinoma HT-29 cells. Blockage of G2/M phase by AITC occurs by modulating Wee1, Chk1, and CDK1/cyclin B signal molecules. ROS production induced by AITC fully facilitates ER stress and mitochondrial apoptotic mechanisms. As a result, ER stress under oxidative stress (ROS production) conditions may contribute to AITC-provoked apoptotic machinery in HT-29 cells. AITC, allyl isothiocyanate; ROS, reactive oxygen species; NAC, N-acetylcysteine; CDK1, cyclin-dependent kinase 1; Chk1, checkpoint kinase 1; GADD153, growth arrest- and DNA damage-inducible protein 153; Apaf-1, apoptotic protease activating factor 1; AIF, apoptosis-inducing factor; Endo G, endonuclease G; ATF-6 $\alpha$, activating transcription factor $6 \alpha$; GRP78, 78 kDa glucose-regulated protein; GRP94, 94 kDa glucose-regulated protein.

In the present study, AITC triggered intrinsic apoptosis in human CRC HT-29 cells via ROS production and ER stress. Moreover, blocking $\mathrm{Ca}^{2+}$-based ER stress signals and ROS formation significantly attenuated AITC-induced HT-29 cell apoptosis. The effective cytotoxic actions of AITC on multiple human cancer cell lines are well documented (12,16-21); however, the detailed mechanisms involved in the cytotoxic effects of AITC in HT-29 cells remain elusive. Our results indicated that AITC inhibited HT-29 cell growth and proliferation. Additionally, AITC induced G2/M phase arrest. This finding is in agreement with that of a study by Lau et al (20) showing that AITC inhibits cell proliferation through the induction of G2/M phase arrest in colorectal adenocarcinoma SW620 cells. AITC has been reported to cause G2/M phase arrest and the disruption of tubulin by decreasing the protein levels of cyclin B1, CDK1, cdc25B, and cdc25C (12,22). Moreover, CDK1 can regulate $\mathrm{G} 2 / \mathrm{M}$ phase progression to stimulate the related signaling in association with cyclin A or cyclin B $(12,43)$. Our results showed that protein levels of CDK1 and cyclin B were decreased and those of Chk1 and Weel were increased following AITC treatment. This finding is consistent with that of previous reports $(12,22,44,45)$ demonstrating that AITC suppresses cell proliferation, possibly through $\mathrm{G} 2 / \mathrm{M}$ phase arrest regulated by Chk1, Wee1, and the cyclin B/CDK1 pathway in HT-29 cells.

AITC was found to facilitate type I programmed cell death (apoptosis) (16-21) or induce autophagy (21) in various types of cancer cell lines. The present study investigated the apoptotic machinery in AITC-treated HT-29 cells. Our data demonstrated that AITC induced apoptotic characteristics, increased the sub-G1 phase (apoptotic) population, and prompted caspase-9/caspase-3 activity. We further verified the anticancer effect of AITC in HT-29 cells by exploring the intrinsic apoptotic mechanism. Consequently, the loss of mitochondrial membrane potential $(\Delta \Psi \mathrm{m})$ has been considered to regulate apoptotic cell fate (37,38). Mitochondrial function is one of the apoptotic mediators that elicit intrinsic signaling $(36,37)$. We demonstrated that AITC facilitated the loss of $\Delta \Psi \mathrm{m}$ and upregulated the molecules of the intrinsic pathway in a concentration-dependent manner. Specifically, this study supported the notion that the activation of the caspase-9/caspase-3-mediated intrinsic pathway caused by AITC treatment in HT-29 cells produced an early response in apoptotic behavior.

ER stress process leads to an accumulation of $\mathrm{Ca}^{2+}$ reservoirs and elicits the secretion of misfolded proteins to induce unfolded protein response (UPR) signaling $(4,37)$. UPR signaling exerts many essential functions via the protein-misfolding capability of the ER undergoing ER stress-mediated cell apoptosis (46). GADD153, also called CHOP (C/EBP homologous protein), is a transcription factor and an initiator of the ER stress-induced apoptotic process (37). Furthermore, the secretion of ER chaperone GRP78, also referred to as binding immunoglobulin protein, is a master monitor of UPR to enhance the cellular misfolding capacity of proteins (47). Here we demonstrated that AITC increased GADD153, GRP78, GRP94 and ATF- $6 \alpha$ protein levels, which are the hallmarks of ER stress. 
AITC-induced ER stress stimulated a rise in intracellular $\mathrm{Ca}^{2+}$ level and activated calpain 1 and caspase-4. The cytosolic $\mathrm{Ca}^{2+}$ release was found to enter mitochondria and then prompt mitochondrial membrane depolarization $(37,38)$. We confirmed that ER stress and $\mathrm{Ca}^{2+}$ release are required in the mitochondrial-dependent apoptosis in HT-29 cells following AITC exposure. Notably, this is the first study to report this finding, which indicates a novel mechanism of AITC-induced ER stress and apoptosis and could enhance the anticancer effect of AITC in CRC cells.

A recent study highlighted that oxidative stress or ROS formation is a critical factor of the stimuli that trigger ER stress-mediated apoptosis (48). The ROS-based ER stress pathway initiates intracellular $\mathrm{Ca}^{2+}$ release via mitochondrial depolarization to manifest apoptosis induction (49). Consistently, our results indicated that AITC treatment increased ROS generation and the antioxidant NAC exhibited a protective effect against AITC. ROS generation was reported to upregulate GADD153/CHOP expression and induce ER stress-mediated apoptosis $(50,51)$. In line with the findings of previous studies $(48,51)$, our data showed that ROS-induced ER stress signaling was involved in AITC-induced caspase-3-dependent apoptosis in HT-29 cells.

In conclusion, our results revealed a novel mechanism by which AITC suppresses human CRC HT-29 cell proliferation, causes G2/M phase arrest, and triggers apoptosis. We demonstrated for the first time that AITC-induced ER stress and cytosolic $\mathrm{Ca}^{2+}$ release occur to modulate intrinsic apoptotic signaling (mitochondrial pathway) in HT-29 cells. These findings clearly support that AITC has a promising therapeutic implication. We hope that the results of this study provide an insight into alternative strategies leading to clinical trials on the treatment of patients with CRC in the near future.

\section{Acknowledgements}

Experiments and data analysis were performed in part through the use of the Medical Research Core Facilities, Office of Research and Development at China Medical University (Taichung, Taiwan).

\section{Funding}

This work was financially supported by Chung-Jen Junior College of Nursing, Health Sciences and Management (grants noo. 105015 and 106-003) and in part by Hualien Tzu Chi Hospital (grant no. TCRD107-55) and China Medical University Hospital (grant no. DMR-108-122).

\section{Availability of data and materials}

The datasets used and/or analyzed during the current study are available from the corresponding author on reasonable request.

\section{Authors' contributions}

JHC, HYC, and JSY were involved in the design of the study, performed the experiments, and drafted the manuscript. JHC and JSY performed the experiments. FJT, YMH, and MCY participated and contributed to the data analysis and review of the manuscript. All authors read and approved the manuscript and agree to be accountable for all aspects of the research in ensuring that the accuracy or integrity of any part of the work are appropriately investigated and resolved.

\section{Ethics approval and consent to participate}

Not applicable.

\section{Patient consent for publication}

Not applicable.

\section{Competing interests}

The authors declare that they have no competing interests.

\section{References}

1. Ferlay J, Colombet M, Soerjomataram I, Dyba T, Randi G, Bettio M, Gavin A, Visser O and Bray F: Cancer incidence and mortality patterns in Europe: Estimates for 40 countries and 25 major cancers in 2018. Eur J Cancer 103: 356-387, 2018.

2. Shen W, Jin Z, Tong X, Wang H, Zhuang L, Lu X and Wu S: TRIM14 promotes cell proliferation and inhibits apoptosis by suppressing PTEN in colorectal cancer. Cancer Manag Res 11: 5725-5735, 2019

3. Ribeiro Gomes J, Belotto M and D'Alpino Peixoto R: The role of surgery for unusual sites of metastases from colorectal cancer: A review of the literature. Eur J Surg Oncol 43: 15-19, 2017.

4. Cheng X, Feng H, Wu H, Jin Z, Shen X, Kuang J, Huo Z, Chen X, Gao H, Ye F, et al: Targeting autophagy enhances apatinib-induced apoptosis via endoplasmic reticulum stress for human colorectal cancer. Cancer Lett 431: 105-114, 2018.

5. Afrin S, Giampieri F, Gasparrini M, Forbes-Hernández TY, Cianciosi D, Reboredo-Rodriguez P, Zhang J, Manna PP, Daglia M, Atanasov AG and Battino M: Dietary phytochemicals in colorectal cancer prevention and treatment: A focus on the molecular mechanisms involved. Biotechnol Adv 38: 107322, 2020.

6. Pan JH, Abernathy B, Kim YJ, Lee JH, Kim JH, Shin EC and Kim JK: Cruciferous vegetables and colorectal cancer prevention through microRNA regulation: A review. Crit Rev Food Sci Nutr 58: 2026-2038, 2018.

7. Vanduchova A, Anzenbacher P and Anzenbacherova E: Isothiocyanate from broccoli, sulforaphane, and its properties. J Med Food 22: 121-126, 2019.

8. Mitsiogianni M, Mantso $T$, Trafalis DT, Vasantha Rupasinghe HP, Zoumpourlis V, Franco R, Botaitis S, Pappa A and Panayiotidis MI: Allyl isothiocyanate regulates lysine acetylation and methylation marks in an experimental model of malignant melanoma. Eur J Nutr 59: 557-569, 2020.

9. Wu CL, Huang AC, Yang JS, Liao CL, Lu HF, Chou ST, Ma CY, Hsia TC, Ko YC and Chung JG: Benzyl isothiocyanate (BITC) and phenethyl isothiocyanate (PEITC)-mediated generation of reactive oxygen species causes cell cycle arrest and induces apoptosis via activation of caspase-3, mitochondria dysfunction and nitric oxide (NO) in human osteogenic sarcoma U-2 OS cells. J Orthop Res 29: 1199-1209, 2011.

10. Kumar G, Tuli HS, Mittal S, Shandilya JK, Tiwari A and Sandhu SS: Isothiocyanates: A class of bioactive metabolites with chemopreventive potential. Tumour Biol 36: 4005-4016, 2015.

11. Abbaoui B, Lucas CR, Riedl KM, Clinton SK and Mortazavi A: Cruciferous vegetables, isothiocyanates, and bladder cancer prevention. Mol Nutr Food Res 62: e1800079, 2018.

12. Tsai SC, Huang WW, Huang WC, Lu CC, Chiang JH, Peng SF, Chung JG, Lin YH, Hsu YM, Amagaya S, et al: ERK-modulated intrinsic signaling and $\mathrm{G}(2) / \mathrm{M}$ phase arrest contribute to the induction of apoptotic death by allyl isothiocyanate in MDA-MB-468 human breast adenocarcinoma cells. Int $\mathrm{J}$ Oncol 41: 2065-2072, 2012.

13. Liu P, Behray M, Wang Q, Wang W, Zhou Z, Chao Y and Bao Y: Anti-cancer activities of allyl isothiocyanate and its conjugated silicon quantum dots. Sci Rep 8: 1084, 2018. 
14. Zhang Y: Allyl isothiocyanate as a cancer chemopreventive phytochemical. Mol Nutr Food Res 54: 127-135, 2010.

15. Qin G, Li P and Xue Z: Effect of allyl isothiocyanate on the viability and apoptosis of the human cervical cancer HeLa cell line in vitro. Oncol Lett 15: 8756-8760, 2018.

16. Jiang Z, Liu X, Chang K, Liu X and Xiong J: Allyl isothiocyanate inhibits the proliferation of renal carcinoma cell line GRC-1 by inducing an imbalance between Bcl 2 and Bax. Med Sci Monit 22: 4283-4288, 2016.

17. Bo P, Lien JC, Chen YY, Yu FS, Lu HF, Yu CS, Chou YC, $\mathrm{Yu} \mathrm{CC}$ and Chung JG: Allyl isothiocyanate induces cell toxicity by multiple pathways in human breast cancer cells. Am J Chin Med 44: 415-437, 2016.

18. Rakariyatham K, Yang X, Gao Z, Song M, Han Y, Chen X and $\mathrm{Xiao} \mathrm{H}$ : Synergistic chemopreventive effect of allyl isothiocyanate and sulforaphane on non-small cell lung carcinoma cells. Food Funct 10: 893-902, 2019.

19. Sávio AL, da Silva GN and Salvadori DM: Inhibition of bladder cancer cell proliferation by allyl isothiocyanate (mustard essential oil). Mutat Res 771: 29-35, 2015.

20. Lau WS, Chen T and Wong YS: Allyl isothiocyanate induces G2/M arrest in human colorectal adenocarcinoma SW620 cells through down-regulation of $\mathrm{Cdc} 25 \mathrm{~B}$ and $\mathrm{Cdc} 25 \mathrm{C}$. Mol Med Rep 3: 1023-1030, 2010

21. Chen HE, Lin JF, Tsai TF, Lin YC, Chou KY and Hwang TI: Allyl isothiocyanate induces autophagy through the up-regulation of Beclin-1 in human prostate cancer cells. Am J Chin Med: Oct 4 2018 (Epub ahead of print). doi: 10.1142/S0192415X18500830.

22. Chen NG, Chen KT, Lu CC, Lan YH, Lai CH, Chung YT, Yang JS and Lin YC: Allyl isothiocyanate triggers G2/M phase arrest and apoptosis in human brain malignant glioma GBM 8401 cells through a mitochondria-dependent pathway. Oncol Rep 24: 449-455, 2010.

23. Lai KC, Lu CC, Tang YJ, Chiang JH, Kuo DH, Chen FA, Chen IL and Yang JS: Allyl isothiocyanate inhibits cell metastasis through suppression of the MAPK pathways in epidermal growth factor-stimulated HT29 human colorectal adenocarcinoma cells Oncol Rep 31: 189-196, 2014.

24. Hwang ES and Lee HJ: Allyl isothiocyanate and its $\mathrm{N}$-acetylcysteine conjugate suppress metastasis via inhibition of invasion, migration, and matrix metalloproteinase-2/-9 activities in SK-Hep 1 human hepatoma cells. Exp Biol Med (Maywood) 231: 421-430, 2006.

25. Thejass $P$ and Kuttan G: Inhibition of endothelial cell differentiation and proinflammatory cytokine production during angiogenesis by allyl isothiocyanate and phenyl isothiocyanate. Integr Cancer Ther 6: 389-399, 2007.

26. Smith TK, Lund EK, Parker ML, Clarke RG and Johnson IT: Allyl-isothiocyanate causes mitotic block, loss of cell adhesion and disrupted cytoskeletal structure in HT29 cells. Carcinogenesis 25: 1409-1415, 2004.

27. Smith T, Musk SR and Johnson IT: Allyl isothiocyanate selectively kills undifferentiated HT29 cells in vitro and suppresses aberrant crypt foci in the colonic mucosa of rats. Biochem Soc Trans 24: 381S, 1996.

28. Musk SR and Johnson IT: Allyl isothiocyanate is selectively toxic to transformed cells of the human colorectal tumour line HT29. Carcinogenesis 14: 2079-2083, 1993.

29. Lu CC, Yang JS, Huang AC, Hsia TC, Chou ST, Kuo CL, Lu HF, Lee TH, Wood WG and Chung JG: Chrysophanol induces necrosis through the production of ROS and alteration of ATP levels in J5 human liver cancer cells. Mol Nutr Food Res 54: 967-976, 2010.

30. Lee HP, Chen PC, Wang SW, Fong YC, Tsai CH, Tsai FJ, Chung JG, Huang CY, Yang JS, Hsu YM, et al: Plumbagin suppresses endothelial progenitor cell-related angiogenesis in vitro and in vivo. J Funct Foods 52: 537-544, 2019.

31. Chang LC, Hsieh MT, Yang JS, Lu CC, Tsai FJ, Tsao JW, Chiu YJ, Kuo SC and Lee KH: Effect of bis(hydroxymethyl) alkanoate curcuminoid derivative MTH-3 on cell cycle arrest, apoptotic and autophagic pathway in triple-negative breast adenocarcinoma MDA-MB-231 cells: An in vitro study. Int J Oncol 52: 67-76, 2018.

32. Chen YA, Shih HW, Lin YC, Hsu HY, Wu TF, Tsai CH, Wu CL, Wu HY, Hsieh JT, Tang CH and Lai CH: Simvastatin sensitizes radioresistant prostate cancer cells by compromising DNA double-strand break repair. Front Pharmacol 9: 600, 2018.

33. Lee CF, Chiang NN, Lu YH, Huang YS, Yang JS, Tsai SC, Lu CC and Chen FA: Benzyl isothiocyanate (BITC) triggers mitochondria-mediated apoptotic machinery in human cisplatinresistant oral cancer CAR cells. Biomedicine (Taipei) 8: 15, 2018.
34. Lin CC, Chen KB, Tsai CH, Tsai FJ, Huang CY, Tang CH, Yang JS, Hsu YM, Peng SF and Chung JG: Casticin inhibits human prostate cancer DU 145 cell migration and invasion via Ras/Akt/NF- $\kappa \mathrm{B}$ signaling pathways. J Food Biochem 43: e12902, 2019.

35. Lin CW, Chin HK, Lee SL, Chiu CF, Chung JG, Lin ZY, Wu CY, Liu YC, Hsiao YT, Feng CH, et al: Ursolic acid induces apoptosis and autophagy in oral cancer cells. Environ Toxicol 34: 983-991, 2019.

36. Chiang JH, Yang JS, Ma CY, Yang MD, Huang HY, Hsia TC, Kuo HM, Wu PP, Lee TH and Chung JG: Danthron, an anthraquinone derivative, induces DNA damage and caspase cascades-mediated apoptosis in SNU-1 human gastric cancer cells through mitochondrial permeability transition pores and Bax-triggered pathways. Chem Res Toxicol 24: 20-29, 2011.

37. Lu CC, Yang JS, Chiang JH, Hour MJ, Lin KL, Lee TH and Chung JG: Cell death caused by quinazolinone HMJ-38 challenge in oral carcinoma CAL 27 cells: Dissections of endoplasmic reticulum stress, mitochondrial dysfunction and tumor xenografts. Biochim Biophys Acta 1840: 2310-2320, 2014.

38. Huang WW, Chiu YJ, Fan MJ, Lu HF, Yeh HF, Li KH, Chen PY, Chung JG and Yang JS: Kaempferol induced apoptosis via endoplasmic reticulum stress and mitochondria-dependent pathway in human osteosarcoma U-2 OS cells. Mol Nutr Food Res 54: $1585-1595,2010$

39. Van der Jeught K, Xu HC, Li YJ, Lu XB and Ji G: Drug resistance and new therapies in colorectal cancer. World J Gastroenterol 24 : 3834-3848, 2018

40. Zhang Y, Xu J, Zhang N, Chen M, Wang H and Zhu D: Targeting the tumour immune microenvironment for cancer therapy in human gastrointestinal malignancies. Cancer Lett 458: 123-135, 2019.

41. Johnson IT: Cruciferous vegetables and risk of cancers of the gastrointestinal tract. Mol Nutr Food Res 62: e1701000, 2018

42. Chang WJ, Chen BH, Inbaraj BS and Chien JT: Preparation of allyl isothiocyanate nanoparticles, their anti-inflammatory activity towards RAW 264.7 macrophage cells and anti-proliferative effect on HT1376 bladder cancer cells. J Sci Food Agric 99: 3106-3116, 2019.

43. Löbrich $M$ and Jeggo PA: The impact of a negligent G2/M checkpoint on genomic instability and cancer induction. Nat Rev Cancer 7: 861-869, 2007.

44. Geng F, Tang L, Li Y, Yang L, Choi KS, Kazim AL and Zhang Y: Allyl isothiocyanate arrests cancer cells in mitosis, and mitotic arrest in turn leads to apoptosis via Bcl-2 protein phosphorylation. J Biol Chem 286: 32259-32267, 2011.

45. Bhattacharya A, Li Y, Geng F, Munday R and Zhang Y: The principal urinary metabolite of allyl isothiocyanate, $\mathrm{N}$-acetyl-S-(N-allylthiocarbamoyl)cysteine, inhibits the growth and muscle invasion of bladder cancer. Carcinogenesis 33: 394-398, 2012

46. Kim C and Kim B: Anti-cancer natural products and their bioactive compounds inducing ER stress-mediated apoptosis: A Review. Nutrients 10: 1021, 2018.

47. Park KW, Eun Kim G, Morales R, Moda F, Moreno-Gonzalez I, Concha-Marambio L, Lee AS, Hetz C and Soto C: The endoplasmic reticulum chaperone GRP78/BiP modulates prion propagation in vitro and in vivo. Sci Rep 7: 44723, 2017.

48. Wang C, Song X, Shang M, Zou W, Zhang M, Wei H and Shao H: Curcumin exerts cytotoxicity dependent on reactive oxygen species accumulation in non-small-cell lung cancer cells. Future Oncol 15: 1243-1253, 2019.

49. Cheng MH, Huang HL, Lin YY, Tsui KH, Chen PC, Cheng SY, Chong IW, Sung PJ, Tai MH, Wen $\mathrm{ZH}$, et al: BA6 Induces apoptosis via stimulation of reactive oxygen species and inhibition of oxidative phosphorylation in human lung cancer cells. Oxid Med Cell Longev 2019: 6342104, 2019.

50. Liao HY, Kao CM, Yao CL, Chiu PW, Yao CC and Chen SC: 2,4,6-Trinitrotoluene induces apoptosis via ROS-regulated mitochondrial dysfunction and endoplasmic reticulum stress in HepG2 and Hep3B cells. Sci Rep 7: 8148, 2017.

51. Yang F, Tang J, Dai K and Huang Y: Metallic wear debris collected from patients induces apoptosis in rat primary osteoblasts via reactive oxygen species-mediated mitochondrial dysfunction and endoplasmic reticulum stress. Mol Med Rep 19: 1629-1637, 2019.

This work is licensed under a Creative Commons Attribution-NonCommercial-NoDerivatives 4.0 International (CC BY-NC-ND 4.0) License. 